\title{
Gamification: Its Pedagogical Innovations Benefit Internship Seekers
}

\author{
Brenda N. Santos - Guevara ${ }^{1 *}$ and Elvira G. Rincon - Flores ${ }^{2}$ \\ ${ }^{1}$ Life and Career Center, Campus de Monterrey, Tecnologico de Monterrey, Mexico \\ ${ }^{2}$ School of Engineering and Sciences, Tecnologico de Monterrey, Mexico
}

\begin{abstract}
Results in higher education and literature have shown that gamification favors intrinsic motivation, cognitive process, and the social aspects of learning by engaging students with their courses. We present the use of a Leaderboard, integrating the used award system, in which students gained badges, built with eleven nicknames, six avatars and seven types of badges. The course Growth-related Competencies aims to prepare students for the search of their internships through tools that allow them to develop professional competencies. This Research was conducted to search for a way to enhance students' performance and quality of done assignments while considering that content seems to be boring and exhaustive for students who review the complete recruitment process (built their resume, have a mock interview, and get familiarized with job boards). We found, through exploratory qualitative research, that students chose an avatar or nickname (optional for students) according to something meaningful for them such as a role model they have or a character with whom they share characteristics according to their self-image. We also learned they found their motivation to participate in gamification as an opportunity to get recognition from teachers and classmates, as well as a reaffirmation of their performance while developing their professional competencies and get prepared to search for their internships. Personal satisfaction, extra points and rewarding were also reasons for them to participate as members of the Leaderboard of the course. Results showed that enhanced gamified design improve student's participation, delivered assignments and quality of hiring products, reflected on final grades.
\end{abstract}

Keywords: Gamification, Leaderboard, Professional Competencies, Internship, Educational Innovation, Higher Education.

\section{Introduction}

Academics are using Gamification as a growing technique to enhance motivation, improve engagement, boost attitude, and contribute to teaching-learning process due to the benefits of a gamified atmosphere gives to all kinds of courses. Based on the idea of the best-used students' preferences and a way to decrease stress-related to learning, homework and school activities (Suhvhqwv et al., 2014), gamification is an acceptable alternative to facilitate serious contexts such as learning ones.

The course Growth-related Competencies aims to prepare students for the search of their internships through tools that allow them to develop professional competencies in such a way in which recruiters can find students' skills beyond hiring process performance (Saunders \& Zuzel, 2010; Suleman, 2016). Because of recruitment process preparation is usually exhaustive, this study points to examine whether this gamification system engaged students with course content with the idea that students complete all their assignments and hiring products with acceptable quality, this means students prepare high-quality products and done on the expected time.

\section{Gamification in Higher Education}

The most familiarized and recognized definition of gamification is the use of game elements on non-game scenarios, such as learning and classrooms, mostly to motivate and increase user activity and engagement 
(Deterding, Dixon, Khaled, \& Nacke, 2011; Dichev \& Dicheva, 2017; Donnell, 2017; Macfarlane \& Tomlinson, 2017; Technologies, 2013).

Educators use gamification based on the idea that game elements turn other scenarios, products, or services more enjoyable and, in this way, gamification assists teachers to help students' involvement with a course or a learning plan. To achieve this goal, gamification design must take into account the special needs pointing three essential elements for gamification: game goal, game rules and lusory attitude (Duncan \& Duncan, 2016). Results will also depend on the suitable content and design according to user-student previous experiences and preferences (Kim, 2015) as well as the solid and clear game goal beyond the design.

Gamification or educational designers must understand the ultimate characteristics of games and elements associated with non-game contexts in which they want to implement gamification when decide on apply it to an entire course or just parts of it (Kennette, College, Beechler, \& College, 2019). Furthermore, designers had to pay special attention to the use of game-like activities to understand if the intended role of gamification is as bait, assessment or as the architecture of engagement (Duncan \& Duncan, 2016). Following the first intention of gamifying an educational experience, game elements are disposed and designed for each scenario.

Researchers (Chapman \& Rich, 2018) found the most preferred gamified elements are those concerning getting points on assignments, flexibility on due dates and penalties, as well as grade indicator. Per types of gamers, a proposition refers to integrate different elements of gamification associated with the four typified kind of gamers: killers, achievers, explorers, and socializers (Kocadere \& Çağlar, 2018). Interaction comes into place through game mechanics which are the game constructs and rules (Nah, Daggubati, Tarigonda, Nuvvula, \& Turel, 2015).

Leaderboards are gamified elements pointed to help students to track their performance (Kennette et al., 2019) related to the group progression on specific activities and, mostly, earned badges. They also provide feedback to students when they participate on gamification voluntary. A function of the leaderboard is to provide an outlook of progression in the gamified design course while the notion of social (class) perception on the achievements motivates some type of students (Jin, Zhang, \& Lu, 2016).

Badges have their contribution to the engagement and motivation because of the fact they show achievements (Gibson, Ostashewski, Flintoff, Grant, \& Knight, 2015). Earned badges are rewards attached to specific goals and requirements, usually visual and textual (Hamari, 2017). Hence, badges help to the socialization and communication of progress on determined behaviors and tasks; this is the reason for showing earned badges through leaderboards, as a way of recognition.

Gamification not only helps to build or design and enjoyable experience, also develop an autonomy sense (Technologies, 2013) when students got the feeling of achievement and competency. Students also interact with their class when they track their progress and get recognition.

\section{Professional Competencies}

A competency is defined as an integration of cognitive and non-cognitive abilities related to performance on the field and discipline. This integration keeps together a mix of the interaction of components of attitude, knowledge, skills, behavior and observed performance on specific criteria when context changes (Zlatkintroitschanskaia, Shavelson, \& Kuhn, 2015). Competency is also an attribute that concerns professions, disciplines, and levels of education (Tobón, 2006) that, sometimes is opposite to grades (Barrett \& Depinet, 1991) because of the implications of competency and their evaluation.

A professional competent person responds to different contexts with appropriateness facts and attitudes. This is the frame to develop professional competencies for future engineers or students of any other major. Specifically, 
universities prioritize the development of competencies to confront industry next generation and soften a rapid change and availability of information and use of technology (Martínez Ruiz, 2019; Molina, 2000; National Academy of Engineering, 2004; Ynzunza et al., 2017).

\section{Background}

Growth-related Competencies course is targeted to prepare students to seek their internships, this means we prepare students for a hiring process as part of the Professional Experience Modality (MEP) that is a complement for their academic program with a credit-internship. For most of the students, this internship search represents their first time participating in recruitments that are typically long, boring, scaring and difficult (Suleman, 2016). In this course, students must prepare all their hiring products such as resume, LinkedIn profile, mock interview, among others. They also need to be familiarized with job boards and work culture. At least half of the students are taking this course at the same time they are seeking for their internships. This is the course context, mainly due to the impossibility to do something different or decrease the number of assignments if we want well-prepared candidates, we look forward to readiness on employability skills and an enjoyable course experience.

In the last period (later referred to as G1), we improved the gamified elements we used in the past to study its effect on this course. The main gamified element was badges as a reward system to recognize students who had an outstanding performance during a few course activities. These earned badges represented extra points to improve final grades. Students were enthusiastic with extra points during the course, but in the end, they were overwhelmed with their final exams and projects from other subjects and the final products of this course, in addition to their hiring process. Most of the times students are involved in from one to three recruitment processes at the same time. This situation caused students to abandon the motivation to earn badges to improve their final grades.

\section{Method}

Growth-related Competencies course was the scenario of the gamified design improvement. We worked with an exploratory qualitative scope and a non-probabilistic sample of nineteen students enrolled in the course on this period. After last experiences with gamification and a real intention to find if there is an impact on students' attitudes and performance on courses like this one, we ask ourselves what else we can do to get the gamification benefits on students. Besides, we aimed to get $100 \%$ of assignments done and students desires to complete them as well as possible under Kim's (2015) recommendations. We intended to trigger all students to do their assignments. Considering that attraction and enjoyable experiences stimulate learning, we looked for a set of elements to update the course in attunement with course purposes on preparing students for work placement and internship seeking.

In this way, the teacher assigned the five performance badges according to clear and communicated criteria, but also students had a voice on three granted badges. The last badge was a recognition to students who completed all the assignments on time and attended during the course.

The first step was to select the course badges, their images, and meaning for course purposes as shown on Table 1. Then, information was published on Blackboard to communicate the pathway to each badge. We have an outdoor activity as part of the course, and we thought it would stimulate participation if students could vote for their classmate's attitude and performance during the challenge. For this activity, three badges were given: resilience, audacity, and realization. 
Table 1: Course badges

\begin{tabular}{|c|c|}
\hline Badge & Course meaning \\
\hline $\begin{array}{l}\text { Effective } \\
\text { communication }\end{array}$ & $\begin{array}{l}\text { This badge represents success in the communication because } \\
\text { it is clear and according to the established criteria during communicative } \\
\text { assignments such elevator pitch, email, and mock interview activities. }\end{array}$ \\
\hline Victory & $\begin{array}{l}\text { This badge represents a triumph. It may be for points or outstanding performance } \\
\text { in contest activities as Winner Resume and LinkedIn. }\end{array}$ \\
\hline Networking & $\begin{array}{l}\text { This badge is won when the network of contacts is increased through various } \\
\text { means. }\end{array}$ \\
\hline Audacity & $\begin{array}{l}\text { You proposed and performed unusual actions, while not jeopardizing your } \\
\text { integrity or your colleagues, contributed to solving the outdoor challenges. }\end{array}$ \\
\hline Realization & We did not expect it! You showed your hidden skills before the outdoor challenge. \\
\hline Resilience & $\begin{array}{l}\text { Outdoor challenge: During your participation in activities and living with your } \\
\text { classmates. } \\
\text { This badge can also be won in the mock Interview. }\end{array}$ \\
\hline Perseverance & $\begin{array}{l}\text { This badge is obtained according to the Attendance to class as well as for the } \\
\text { Punctuality in the delivery of activities. }\end{array}$ \\
\hline
\end{tabular}

The first gamified assignment for students was to select either an avatar or a nickname to set their identity on the leaderboard. Students had to submit their election and the reason for it. We reviewed student's responses to the question "why did you choose this identity?"

To process data from student's grades, we used a t-test to compare final grades obtained on two courses to track the impact of the enhanced design on student's performance using http://vassarstats.net. Student's attitudes were recorded through direct observation, student's comments, and their hiring products. On the first course (G1) the only gamified element were badges, while in the second one (G2) we integrated leaderboard and a straight definition of badges and criteria (enhanced design). We also asked students their satisfaction on a Likert-scale online survey at the end of the course. These results were processed to get frequency on answers.

\section{Results and Discussion}

We had eleven nicknames and six avatars to integrate the leaderboard with seven badges. Students were free to choose from both options to set their identity on the leader board. Figure 1 shows the look of the leaderboard at the end of the course with all identities and won badges. We had a student who won most of the badges, and a few students who got the same badges in different activities. For example, the networking badge could be won according to their LinkedIn profile improvement and the number of contacts they got in a career fair we had on the campus. Perseverance was given to students who always attended class on time and did their assignments, this badge was not grading representative.

We integrated elements for three of the types mentioned by Kocadere \& Çağlar (2018): the leaderboard for killers, a reward for achievers and explorers. This gave us the opportunity to impact students' motivation on different stimuli and personalities. As well as leader board had the feature to show progress among students on this course and motivate them to participate to get more badges (see Figure 1). 


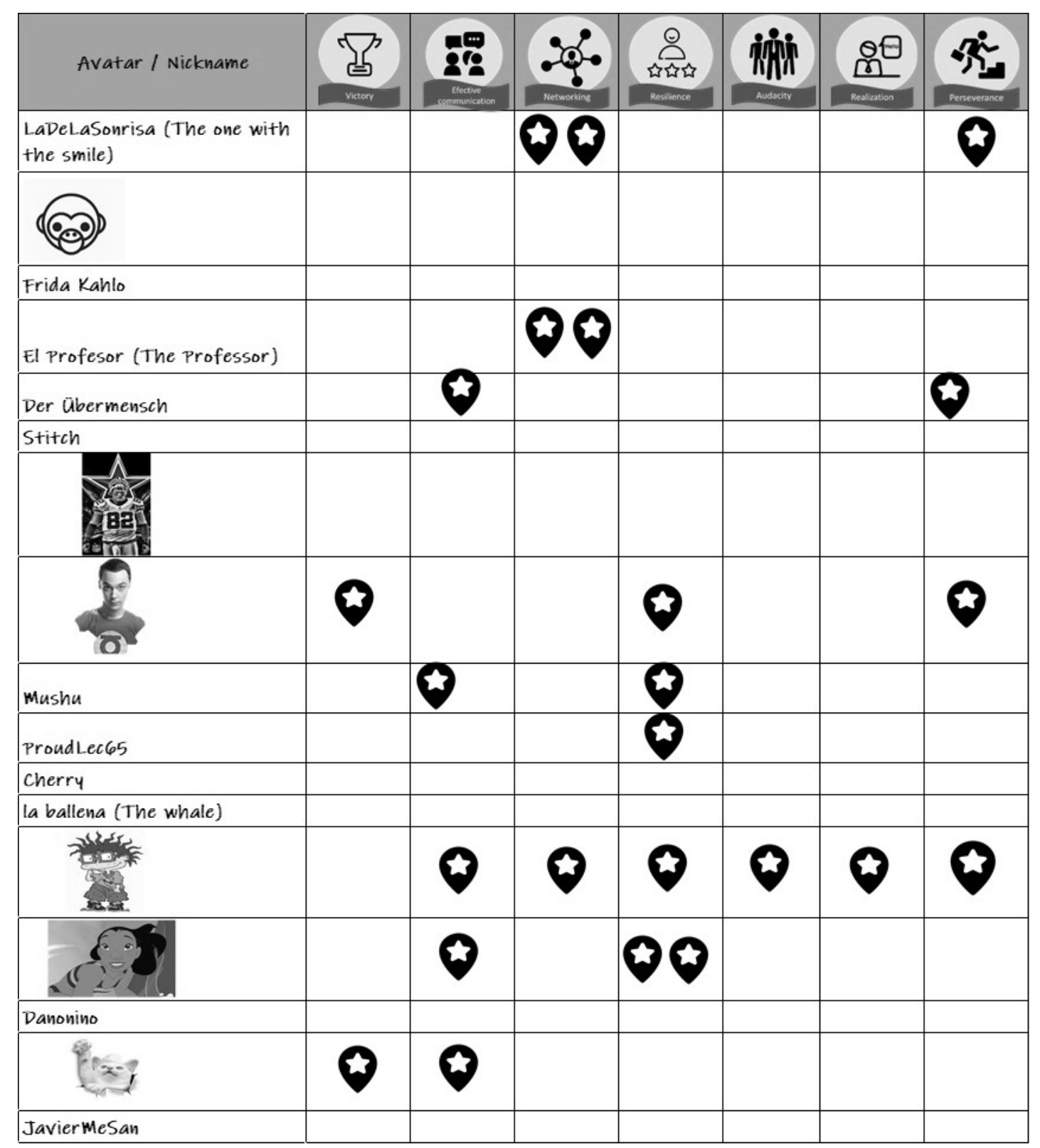

Figure 1. Leaderboard at the end of the course

When we asked students "why did they choose their nickname or avatar?", we found a tendency to select something meaningful for them. It was revealing for us to understand identities to represent themselves (see Figure 2). Although some of them forgot their identity on the leaderboard, most of them depicted their skills, abilities, or incentives to improve and reinforce their attitudes and outcomes. We also found that students were proud of their performance and the badges they got. In particular, the student who got most of the badges wanted everyone to know it was him. But he also liked to be anonymous until the end of the course. In this case, peers voted for him on the outdoor challenge, and his attitude improved on the rest of the course, he was proud of him but also self-confident once he was voted.

We observed students had a better attitude toward the course compared with other courses when they complained about the number and frequency of the assignments. Students paid attention and even if they did not have the best grade in an activity, they were more interested on their progress than students were in past courses where they wanted the best grade above competition and performance. The concerns were about fulfilling requirements for a job search and hiring product quality. This let us think we had an advance on the first 
question we had to trigger students' participation according to Chapman and Rich (2018) who reported results in which students who participate in gamified courses were more willing to participate on class activities (see Figure 2).

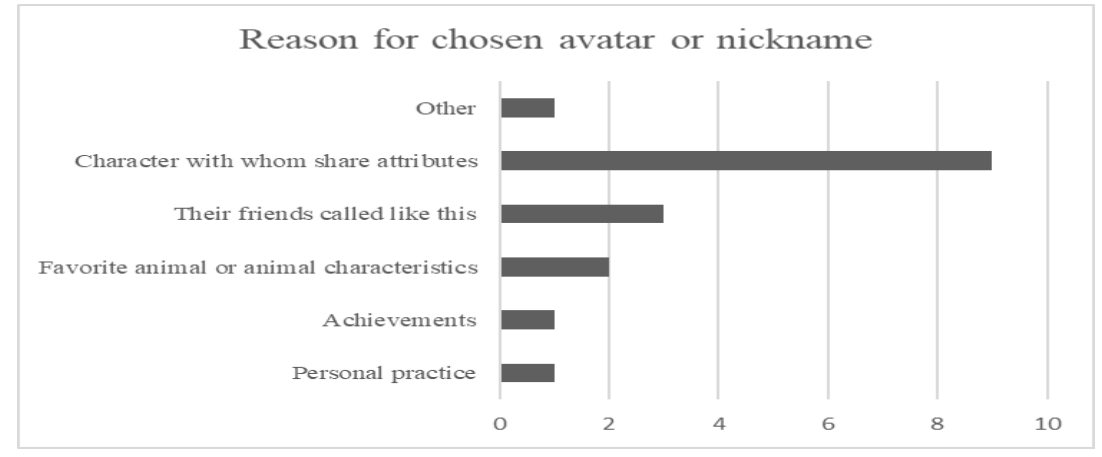

Figure 2. Reason for identity selection

When we asked students their motivation to participate in the leaderboard and tried to earn badges, they said personal satisfaction was the most important reason because they saw it as an opportunity to get recognition for their effort. They still wanted the best grade at the end of the course, but extra points were not the most important reason or even needed, most of the final grades were near to the maximum (see Table 2).

Table 2: Likert scale answer frequencies.

\begin{tabular}{|l|l|l|l|l|l|}
\hline Question & $\begin{array}{l}\text { Strongly } \\
\text { agree }\end{array}$ & Agree & Neutral & Disagree & $\begin{array}{l}\text { Strongly } \\
\text { disagree }\end{array}$ \\
\hline $\begin{array}{l}\text { Did the course rewards (badges) system, } \\
\text { motivate you to participate in class and / or } \\
\text { do the course activities? }\end{array}$ & $61.54 \%$ & $15.38 \%$ & $15.38 \%$ & $0 \%$ & $7.69 \%$ \\
\hline $\begin{array}{l}\text { Does the course rewards (badges) system, } \\
\text { must remain anonymous until the end of } \\
\text { the course? }\end{array}$ & $71.43 \%$ & $7.14 \%$ & $14.29 \%$ & $0 \%$ & $7.14 \%$ \\
\hline $\begin{array}{l}\text { Do you think the course reward system } \\
\text { (badges) is related to the course? }\end{array}$ & $64.29 \%$ & $14.29 \%$ & $14.29 \%$ & $0 \%$ & $7.14 \%$ \\
\hline $\begin{array}{l}\text { Do you consider the policies for assigning } \\
\text { badges in the course are adequate? }\end{array}$ & $45.45 \%$ & $27.27 \%$ & $18.18 \%$ & $0 \%$ & $9.09 \%$ \\
\hline $\begin{array}{l}\text { Are you satisfied with the badges that were } \\
\text { awarded during the course? }\end{array}$ & $41.67 \%$ & $33.33 \%$ & $16.67 \%$ & $0 \%$ & $8.33 \%$ \\
\hline $\begin{array}{l}\text { The leadership dashboard let you know } \\
\text { which badges you earned? }\end{array}$ & $64.29 \%$ & $14.29 \%$ & $14.29 \%$ & $0 \%$ & $7.14 \%$ \\
\hline $\begin{array}{l}\text { The timing of each badge awarded was } \\
\text { appropriate? }\end{array}$ & $57.14 \%$ & $21.43 \%$ & $7.14 \%$ & $7.14 \%$ & $7.14 \%$ \\
\hline
\end{tabular}

We got more than $40 \%$ of satisfaction on the questions we did them on the Likert Scale. In general, there were a perception of satisfaction by observance and comments, but on numbers we have weaknesses to attend. An opportunity is that we did not communicate the won badges at the best time (it took more than one class). Only $41.67 \%$ is satisfied with the awarded badges on the course, while $16.67 \%$ is neutral. Although they said in their comments they were satisfied with this experience, students wanted to get more badges that they did, but they did not express how they would prefer to win badges, or if it was clear for them how to win and type of badges they would prefer on the course. We did not expect these results, so we did not ask students what they wanted to express or how to improve their satisfaction. Besides, $61.54 \%$ of students answered (strongly agree) gamification motivated them to do course assignments and found the reward system connected to the course. 
In all the questions, we had a student who answered, "Totally disagree", he was not satisfied with the course gamification and he either got a badge. On the other hand, $45.45 \%$ strongly agreed on the appropriateness of the way we assigned badges. This is another opportunity to reinforce the strategy. This means we need to be clear with the badge's assignation to improve student's satisfaction with the assigned badges. Besides, we need to ask them why they were not satisfied. Moreover, clarify if it was clear for them how to get a specific badge and help students who did not win badges to get one. Rules must be clear for students and, there is a good idea to explain to them or show them the winner products (assignments) as a way of set transparency and make it clear for students who do not won badges.

In the aim to improve student's performance and tasks' qualities, we got positive results translated on final grades. Even when students in both courses (G1 and G2) had good final grades, students on G2 had a better performance (referenced as final grades where $\mathrm{XG} 2=97.92$, $\mathrm{XG1}=91.31, \mathrm{p}=0.0055$, as shown on Table 3). For this reason, we can conclude that the implementation worked not only on teacher's perception, also in numbers when we got significance difference between groups. Students completed more assignments during this course (G2) than the last one (G1) as shown in Figure 3 in which we only considered the awarded assignments to compare if the delivered percentage was improved or not and grades. Although the difference is small on number, we gained on quality, average grades were higher on G1 compared to G2, except for winner resume delivery and grade, this assignment consisted of take an online five questions quiz after class. This means, for us, there was a development of professional competencies due to students concerns on complete tasks beyond the activity grade but also because of their grades.

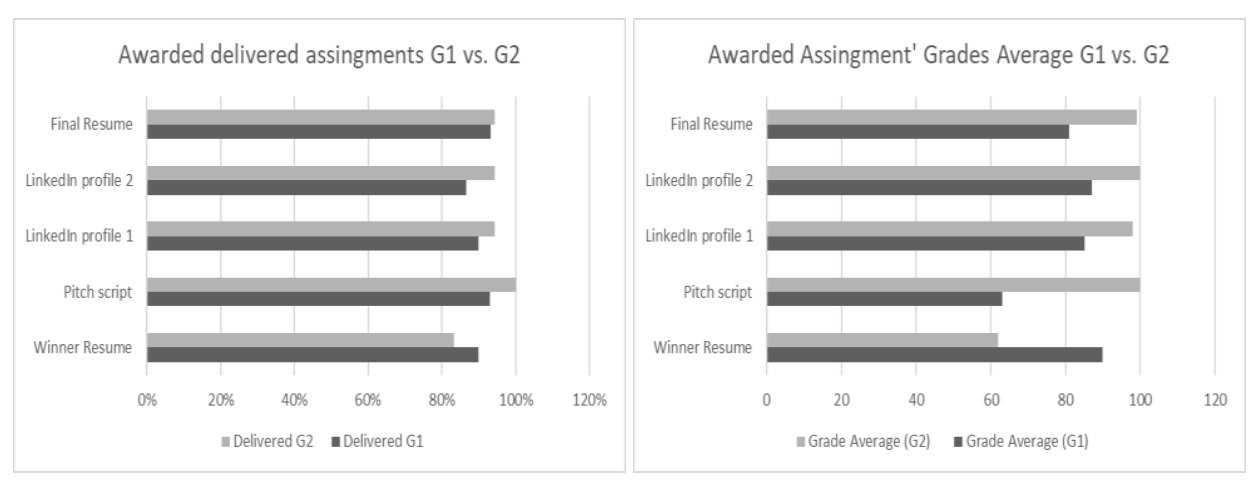

Figure 3. Percentage of delivered assignments and its grades, comparing G1 and G2.

Figure 3 does not show the outdoor challenge activity and its badges, neither perseverance badge, but it is appropriate to see students began on a lower participation and increased during the course. Students were better integrated on G2 than G1 before the outdoor challenge and class environment was even more enjoyable after voting for classmates. They worked together, help each other to solve the challenges, and recognized their peers for their performance and attitude. As mentioned before, the student who won the three badges for the outdoor challenge, changed his attitude to classmates and self-confidence after being recognized. The final resume is a challenge due to specific corrections and due date near to other subject final projects and exams. In some cases, students felt confident on their resume because they already went part of recruitment processes.

Table 3: $t$-Test results for $G 1$ and G2.

\begin{tabular}{|l|l|l|l|}
\hline \multirow{2}{*}{} & \multirow{2}{*}{ Observed } & \multicolumn{3}{|l|}{ Confidence intervals } \\
\cline { 3 - 4 } & & 0.95 & 0.99 \\
\hline Meana & 91.3131 & \pm 3.3136 & \pm 4.4613 \\
\hline Meanb & 97.9256 & \pm 3.3384 & \pm 4.5884 \\
\hline Meana - Meanb [Assuming equal sample variances.] & -6.6125 & \pm 4.8314 & \pm 6.4659 \\
\hline Meana - Meanb [Assuming unequal sample & -6.6125 & \pm 4.569 & \pm 6.1071 \\
\hline
\end{tabular}




\begin{tabular}{|l|l|l|l|}
\hline variances.] & & & \\
\hline & Independent samples \\
\hline
\end{tabular}

Limitations on this study are related to students enrolled on this course and their answers. Also, data collection was a limitation because it was conducted by observation, students' comments, and online survey. Even when it was mandatory to answer the questions, three of them did not answer. The rest of the answers sometimes were contradictory, results were not always in concordance with oral comments during classes or in personal conversations. By the other hand, there is an impossibility to clearly conclude results are merely due to gamification without considering students number and preferences. Gamified assignments reminded the same, but also changes on classes had an effect we are not able to compute.

\section{Conclusions}

The resulted scheme to answer both research questions, how get benefits from gamification and how to trigger students to do all the course assignments, was a reinforcement-gamified experience with an improved reward system that included a leaderboard to socialize and track progress on course tasks. On this way we were able to show anonymous identities for each participant who accepted to participate. Furthermore, we encouraged the student's involvement with the election of their identities and votes for three of the seven badges.

We observed students improved on their course engagement when they were concerned with the quality of their hiring products instead of grades. Grades were still important to them but to complete all recruitment and course requirements. Besides, we saw how students' attitudes enhanced when they were recognized on the group for achievements and these achievements were socialized. Even when they forgot their leader board identity, they were proud of the challenges they had to do and had a familiar attachment to their avatar or nickname, according to the case.

We integrated elements for three of the types mentioned by Kocadere \& Çağlar (2018): the leaderboard for killers, a reward for achievers and explorers. We can improve a quest or story to get an element for socializers. Although, according to other authors' recommendations, teams work for socializers, in this way we can consider the outdoor challenge activity as the element for socializers since they work on teams.

Considering engagement, involvement, quality, and active participation and interaction, results are concluding in this case in which students improved quality and delivered number of assignments. To encourage the next step in improving and testing results of gamified experiences when looking to prepare internship seekers, we propose to reinforce the gamified scenario, if possible, using an specific narrative that can be integrated on the leader board to show progress but also a sense of competition on a story or goal beyond course objectives to stress narrative and theme as predominant game elements on the course, but not limited to an award system.

Our next steps are communicating on appropriated time the won badges and the giving rules. As well as take this experience to improve the gamified design once we conclude by observation and statistics, there was an impact on grades, attitude, and students' performance. By the moment, we are reinforcing strategies. Students not only wanted extra points, but they also needed recognition for their effort and improvements.

\section{Acknowledgments}

The authors would like to acknowledge the financial and technical support of Writing Lab, TecLabs, Tecnologico de Monterrey, Mexico, in the produc5on of this work.

Authors also would like to acknowledge Career Advisors from Life and Career Center, Campus Monterrey, for their valuable collaboration during interview practice. 


\section{References}

Armstrong, M. B., \& Landers, R. N. (2017). An Evaluation of Gamified Training: Using Narrative to Improve Reactions and Learning. Simulation and Gaming, 48(4), 513-538. https://doi.org/10.1177/1046878117703749

Barrett, G. V., \& Depinet, R. L. (1991). A reconsideration of testing for competence rather than for intelligence. American Psychologist, 46(10), 1012-1024. https://doi.org/10.1037/0003-066X.46.10.1012

Chapman, J. R., \& Rich, P. J. (2018). Does educational gamification improve students' motivation? If so, which game elements work best? Journal of Education for Business, 93(7), 314-321. https://doi.org/10.1080/08832323.2018.1490687

Deterding, S. (2011). Gamification : Toward a Definition, 12-15.

Donnell, N. O. (2017). How Multidisciplinary is Gamification Research ? Results from a Scoping Review, 445452.

Duncan, S. C., \& Duncan, S. C. (2016). “ Games with learning ": adpositions and the lusory attitude, 24(3), 246-256. https://doi.org/10.1108/OTH-04-2016-0020

Gibson, D., Ostashewski, N., Flintoff, K., Grant, S., \& Knight, E. (2015). Digital badges in education. Education and Information Technologies, 20(2), 403-410. https://doi.org/10.1007/s10639-013-9291-7

Hamari, J. (2017). Do badges increase user activity? A field experiment on the effects of gamification. Computers in Human Behavior, 71, 469-478. https://doi.org/10.1016/j.chb.2015.03.036

Jin, L., Zhang, K., \& Lu, J. (2016). Towards understanding the gamification upon users ' scores in a locationbased social network. Multimedia Tools and Applications, 8895-8919. https://doi.org/10.1007/s11042-0142317-3

Kennette, L. N., College, D., Beechler, M. P., \& College, A. (2019). Gamifying The Classroom : Tips from the Trenches, 12(2), 1-9.

Kim, B. (2015). Designing Gamification in the Right Way. Library Technology Reports, 29-36.

Kocadere, S. A., \& Çağlar, Ş. (2018). Gamification from Player Type Perspective : A Case Study, 21, 12-22.

Molina, A. (2000). La Competencia Profesional en el Ingeniero del Nuevo Milenio. Revista Facultad de Ingeniería, (8), 65-71.

Nah, F. F.-H., Daggubati, L. S., Tarigonda, A., Nuvvula, R. V., \& Turel, O. (2015). Effects of the use of points, leaderboards and badges on in-game purchases of virtual goods. Lecture Notes in Computer Science (including subseries Lecture Notes in Artificial Intelligence and Lecture Notes in Bioinformatics) (Vol. 9191). https://doi.org/10.1007/978-3-319-20895-4_48

Roy, R. Van. (2018). Uses and Gratifcations of Initiating Use of Gamifed Learning Platforms, 1-6.

Saunders, V., \& Zuzel, K. (2010). Evaluating Employability Skills: Employer and Student Perceptions. Bioscience Education, 15(1), 1-15. https://doi.org/10.3108/beej.15.2

Suhvhqwv, D., Dffrxqw, D. U., Krz, R. I., Fdwlrq, J., Khos, F. D. Q., \& Ryhufrph, V. (2014). REFLECTION : BENEFITS OF GAMIFICATION IN, 125-132.

Suleman, F. (2016). Employability Skills of Higher Education Graduates: Little Consensus on a Much-discussed Subject. Procedia - Social and Behavioral Sciences, 228(June), 169-174. https://doi.org/10.1016/j.sbspro.2016.07.025

Technologies, L. (2013). gameful learning Design, (July).

Tobón, S. (2006). Aspectos básicos de la formación basada en competencias, 1-16.

Zlatkin-troitschanskaia, O., Shavelson, R. J., \& Kuhn, C. (2015). The international state of research on measurement of competency in higher education, 40(3), 393-411. 